\title{
Planning for the Future: A Life Management Strategy for Increasing Control and Life Satisfaction in Adulthood
}

\author{
Kimberly M. Prenda and Margie E. Lachman \\ Brandeis University
}

\begin{abstract}
The study examined the social, personality, and cognitive correlates of self-reported future planning and the relationship of future planning to perceived control and life satisfaction. Using 2 probability samples of adults ages $25-74\left(n^{1}=2,971, n^{2}=300\right)$ findings suggest, for Study 1, that education, income, social support, predictability, Conscientiousness, and Openness to Experience were positively related to future planning, whereas Neuroticism and Agreeableness were negatively related. Men were more future oriented; as age increased, future planning decreased. Study 2 replicated the findings with the exception of age, Agreeableness, and Neuroticism. For both studies, results supported a model in which the effects of future planning on life satisfaction were mediated by sense of control. A Planning $\times$ Age interaction for Study 1 indicated that although self-reported future planning decreased with age, the positive effects of future-oriented planning strategies on life satisfaction were most pronounced for the older adults, and this relationship was also mediated by control beliefs.
\end{abstract}

Psychologists have long been interested in the ways in which people control or structure their lives and how those different strategies influence outcomes. Planning, as a life management strategy, is one way people control and structure their lives. Often we are advised not to count our chickens before they hatch or that a "one-day-at-a-time" approach to life may yield more positive outcomes. According to Cameron, Desai, Bahador, and Dremel (1977-1978) even the Bible tells us "Do not be anxious about tomorrow, tomorrow will look after itself. Each day has troubles enough of its own" (Matthew 6:34, King James Version). In contrast, the view that by planning for the future we ensure direction, control, and a greater sense of well-being in our lives is espoused by western cultural views. Take, for example, the recent trend of hiring personal planners for everything from weddings to vacations and the large inventory of day planners in office supply and computer stores (Kunde, 1998).

The goals of the present study were twofold: (a) to examine individual differences in self-reported future planning in relation to environmental, personality, and cognitive antecedents and (b) to investigate the relationship of future-oriented planning to perceived control and life satisfaction. Further, this study examined whether the nature of that relationship varied by age. The extensive research literature on planning falls into two broad categories: (a) those involving problem-solving processes and planning of discrete, finite tasks (e.g., Das, Kar, \& Parilla, 1996; G. A. Miller, Galanter, \& Pribram, 1960; Smith, 1996) and (b) those that explore

Kimberly M. Prenda and Margie E. Lachman, Department of Psychology, Brandeis University.

This research was supported by The John D. and Catherine T. MacArthur Foundation Research Network on Successful Midlife Development (MIDMAC) and National Institute on Aging Grant AG 17920.

Correspondence concerning this article should be addressed to Margie E. Lachman, Department of Psychology, Brandeis University, Waltham, Massachusetts 02254. Electronic mail may be sent to lachman@ brandeis.edu. more open-ended, generalized life-planning tasks (e.g., Cantor, 1990; Little, 1983; Nurmi, 1989; Smith, 1996). This study focused on the latter approach by assessing self-reported planning styles.

Process models of planning (e.g., S. L. Friedman \& Scholnick, 1997; Macan, 1994; Scholnick \& Friedman, 1993) suggest possible antecedents and outcomes of planning in both the problemsolving and life-planning domains. S. L. Friedman and Scholnick's model is one in which "multiple component skills, evoked by different sets of psychological and environmental circumstances," (p. 12) work together to influence each other and the planning process. Their full model identifies components of culture, task, environment, cognitive, and personality domains; their influences on each other; and what they deem to be the essential qualities necessary for planning. Inadequate resources within these domains will result in negative consequences for planning. With this model as a guide, although limited by the archival and cross-sectional nature of the available data, this study examined, as a first step, a selection of identified antecedents or precursors of planning from the domains of environmental factors, personality, and cognition, and their relationship to future-oriented planning.

\section{Who Plans?}

Demographic factors of age, sex, education, and income should be considered and controlled for in an investigation of the precursors and outcome variables related to planning strategies of life management. Studies of age and sex differences in future planning, as measured by various specific problem-solving (e.g., Tower of Hanoi, party planning) or generalized futurity measures such as line-drawing tasks, have produced inconsistent findings (e.g., Bouffard, Bastin, \& Lapierre, 1996; Burack \& Lachman, 1995 Kastenbaum, 1963; Lens \& Gailly, 1980; Lowenthal, Thurnher, \& Chiriboga, 1975; Nurmi, 1992; Nuttin \& Lens, 1985; Rakowski, 1979; Spence, 1968). In contrast, research on education and income in relation to future planning has consistently found a significant, positive association (Nurmi, 1992; Schneiderman, 1964; Teahan, 1958). The present study examined demographic variables 
by using a nationally representative data set to more fully understand their relationship to daily life management planning across the adult life span.

Research also indicates that self-reports of predictability of one's environment (M. I. Friedman \& Lackey, 1991), leading to an enhanced sense of control over one's future, and the perceived quantity and quality of available social support, providing a sense of help and guidance in novel situations (Bronfenbrenner, 1979; Goodnow, 1997; Hudson, Sosa, \& Shapiro, 1997; Rogoff, 1990; Trommsdorff, Lamm, \& Schmidt, 1978), are positively associated with increased planning and more effective planning of taskspecific goals as well as generalized futurity of planning. It was therefore expected that operating within a predictable and supportive environment might facilitate future planning.

Additional antecedents included elements of personality and motivation. Previous research investigating personality and planning has been inconsistent (see Robertson, 1978, for a review; Lessing, 1968). In accordance with S. L. Friedman and Scholnick's (1997) model, and as an expansion on previous research, this study investigated the Big Five personality constructs (McCrae \& Costa, 1985) to assess individual differences in personality that may be associated with future-oriented life management planning styles. The experience of stress has also been shown to have a negative impact on the cognitive components of planning, namely, information processing (Kopp, 1997; Locke, Durham, Poon, \& Weldon, 1997). Therefore, we postulated a negative association between self-reported occurrence of stressful life events and planning.

We examined two cognitive factors as antecedents of planning. Both working memory (S. L. Friedman \& Scholnick, 1997; Haith, Benson, Roberts, \& Pennington, 1996) and simultaneous and successive processing, involved in problem solving and reasoning (Das et al., 1997; S. L. Friedman \& Scholnick, 1997; Luria, 1966), have been shown to be positively related to planning. According to Haith et al. (1996), "Planning . . involves selecting and sequencing some actions and inhibiting others and hence requires WM [working memory]" (p. 260). Similarly, the ability to process or reason about a problem or situation in a simultaneous and successive manner is necessary for the development of effective plans (S. L. Friedman \& Scholnick, 1997). Thus, we expected working memory and problem-solving/reasoning abilities to be positively related to future-planning styles.

\section{Planning, Perceived Control, and Life Satisfaction}

A second focus of this study was the association of planning style, perceived control, and life satisfaction. Previous findings suggest that planning is associated with such constructs as selfefficacy, motivation, volition, effort, and persistence (Aspinwell, 1997; Bandura, 1997; Gollwitzer, 1996; Kirschenbaum, Humphrey, \& Malett, 1981; Kuhl, 1984; Lachman \& Burack, 1993; Skinner, 1997; Thompson, Cheek, \& Graham, 1988). These findings, examined in conjunction with research suggesting a positive relationship between future-oriented planning and life satisfaction (Burack \& Lachman, 1996; Spence, 1968; Trommsdorff, 1994), suggest that planning leads to a greater sense of control and to an increase in perceptions of well-being.

There also exists a large body of work on control and its impact on well-being (e.g., Brandtstädter \& Baltes-Gotz, 1990; Bond \&
Feather, 1988; Eronen, Nurmi, \& Salmela-Aro, 1997; Lachman \& Burack, 1993; Lachman \& Weaver, 1998; Macan, 1994; Macan, Shahani, Dipboye \& Phillips, 1990). Most findings suggest a positive relationship between perceived control and both physical and mental well-being.

The first goal of the present study was to investigate the relationship between some essential antecedents of planning (S. L. Friedman \& Scholnick, 1997) and participants' self-reported planning style in order to test some key elements of S. L. Friedman and Scholnick's planning model based on earlier work from both the child and adult development literature. Planning was operationalized as the degree to which participants reported that they make plans for the future and set goals as opposed to focusing on today and living 1 day at a time. On the basis of previous research outlined above, we hypothesized that higher scores for both working memory and problem-solving/reasoning measures, higher social support and predictability, and fewer self-reported stressful events would be predictive of future-oriented planning. Because of the inconsistent findings of previous research, the Big Five personality constructs were investigated with no a priori predictions. This study also hypothesized that age would have a negative relationship with planning; that is, as age increased, futureoriented planning was expected to decrease. Previous research has shown women to be more short-term, listmaking planners (Burack \& Lachman, 1996). Because the present study measured more generalized future planning we expected to find that men would be more future oriented in their planning than women. We also expected that those participants with higher education and income would report more future-oriented planning.

The second goal of this study was to examine the relationship between self-reported planning style, perceived control, and life satisfaction. Future planning was expected to be positively associated with perceived control and life satisfaction. The interaction between age, planning, and life satisfaction was also examined to more fully explore whether the impact of planning on life satisfaction varied across the adult life span. Additionally, the relationship between planning and life satisfaction was expected to be mediated by a sense of control.

\section{Method}

To enable replication and extension of the results, two separate, existing data sets were used to examine antecedents and outcomes associated with planning. For both, participants were questioned regarding their general approach to planning as part of a larger questionnaire.

\section{Participants}

Study 1. Participants of Study 1 were 3,032 respondents of the Midlife Development in the United States (MIDUS) study conducted by the John T. and Catherine D. MacArthur Foundation. Participants were initially obtained through random digit dialing procedures. Forty-nine percent of the respondents were male, ages 25 to 75 years old $(M=46.9, S D=13.1)$. Eighty-eight percent of the participants were White and fairly well educated, with $16 \%$ reporting at least a 4 -year college degree. Participant information was obtained via the Midlife Development Inventory (MIDI; see Lachman \& Weaver, 1998) consisting of two mailed, self-report questionnaires (Part I and Part II), as well as a 20-30 min telephone interview. The phone interview was conducted first, after which the two mailed questionnaires were sent. Of the 3,032 original participants of the MIDUS study, 2,971 (98\%) had complete data and were included in the 
Table 1

Means, Standard Deviations, and Pearson Correlations for All Variables in Study 1 (Above Diagonal) and Study 2 (Below Diagonal)

\begin{tabular}{|c|c|c|c|c|c|c|c|c|c|c|}
\hline \multirow[b]{2}{*}{ Variable } & \multicolumn{2}{|c|}{ Study 1} & \multicolumn{2}{|c|}{ Study 2} & \multirow[b]{2}{*}{1} & \multirow[b]{2}{*}{2} & \multirow[b]{2}{*}{3} & \multirow[b]{2}{*}{4} & \multirow[b]{2}{*}{5} & \multirow[b]{2}{*}{6} \\
\hline & $M$ & $S D$ & $M$ & $S D$ & & & & & & \\
\hline 1. Age & 46.9 & 13.10 & 47.90 & 13.20 & - & $.04 *$ & $-.10 * * *$ & .02 & $.09 * * *$ & $-.08 * * *$ \\
\hline 2. Gender ${ }^{\mathrm{a}}$ & 1.51 & 0.50 & 1.41 & 0.49 & -.08 & - & $-.09 * * *$ & $-.16 *$ & $.07 * * *$ & $-.05 * *$ \\
\hline 3. Education & 6.8 & 2.50 & 7.7 & 2.60 & -.05 & -.04 & - & $.33 * * *$ & $.06 * * *$ & $.14 * * *$ \\
\hline 4. Income & 54,930 & 48,632 & 73,398 & 61,441 & .07 & -.05 & $.36 * * *$ & - & $.09 * * *$ & $.09 * * *$ \\
\hline 5. Support & 3.4 & .48 & 3.4 & .52 & .05 & $.13 *$ & .06 & .10 & - & $.10^{* * *}$ \\
\hline 6. Predictability & 2.3 & .89 & 2.4 & .86 & -.08 & $-.14 * *$ & .02 & .02 & $.11^{*}$ & - \\
\hline 7. Agreeableness & 3.5 & .48 & 3.4 & .54 & .07 & $.22 * * *$ & -.11 & -.07 & $.26^{* * *}$ & $.17^{* * *}$ \\
\hline 8. Conscientiousness & 3.4 & .45 & 3.4 & .44 & .09 & $.17 * *$ & $.13 *$ & $.13 *$ & $.30 * * *$ & $.16^{* *}$ \\
\hline 9. Extraversion & 3.2 & .57 & 3.2 & .51 & .00 & .05 & .00 & .04 & $.24 * * *$ & $.22 * * *$ \\
\hline 10. Neuroticism & 2.2 & .66 & 2.2 & .65 & $-.11^{*}$ & .05 & $-.14 *$ & $-.14 *$ & $-.26 * * *$ & .05 \\
\hline 11. Openness & 3.0 & .52 & 3.0 & .49 & -.08 & $-.12^{*}$ & $.24 * * *$ & .09 & $.12 *$ & $.28 * * *$ \\
\hline 12. Stressful Events & -.01 & 1.00 & -.01 & .79 & $.14 *$ & .03 & $-.11 *$ & -.06 & $.12^{*}$ & -.01 \\
\hline 13. Memory ${ }^{b}$ & & & .02 & .77 & -.07 & $-.22 * * *$ & $.30^{* * *}$ & $.20 * * *$ & .03 & .01 \\
\hline 14. Reasoning ${ }^{\mathrm{b}}$ & & & -.00 & .90 & $-.40^{* * *}$ & .07 & $.44 * * *$ & $.35 * * *$ & .04 & -.03 \\
\hline 15. Planning & 2.9 & .58 & 2.9 & .61 & -.05 & $-.16 * *$ & $.38 * * *$ & $.31 * * *$ & $.19 * * *$ & $.20 * * *$ \\
\hline 16. Control & 5.5 & 1.00 & 5.6 & .94 & -.11 & -.07 & $.22 * * *$ & $.14 *$ & $.36^{* * * *}$ & $.17 * *$ \\
\hline 17. Life Satisfaction & 7.6 & 1.30 & 7.6 & 1.40 & .14 & .03 & .07 & $.21^{* * *}$ & $.42 * * *$ & .06 \\
\hline
\end{tabular}

${ }^{a}$ For gender, $1=$ male, $2=$ female. ${ }^{\mathrm{b}}$ Memory and reasoning were in Study 2 only.

$* p<.05 . \quad * * p<.01 . \quad * * * p<.001$.

present analyses (see Lachman \& Weaver, 1998, for additional sample information).

Study 2. As part of the MIDUS sampling frame, additional names were drawn for an oversample in the Greater Boston metropolitan area. The 302 participants from the Boston area study also had MIDI data as described above, but they were not included in the Study 1 analyses. In addition, the Boston participants also agreed to two telephone interviews and one in-person interview. Cognitive assessments obtained during the in-person portion of the follow-up study were used in addition to the data from the MIDI. Fifty-six percent of the participants were male, ages 25 to 75 years old $(M=47.9, S D=13.2)$. Ninety-two percent of them were White. Twenty-three percent reported a minimum of a 4-year college degree. Each participant was paid $\$ 25$ for each of the three interviews. The interviews were conducted over a 2-year period with approximately 6 to 8 months between each interview. Of the original 302 participants, $300(99 \%)$ had complete data and were included in the analyses.

\section{Measures}

Age. Age was assessed in chronological years. Age was used both as a continuous variable and recoded as a categorical variable with three groups: young $=25-39$ years, middle $=40-59$ years, and old $=60-75$ years.

Gender. Gender was a dichotomous variable: $1=$ male and $2=$ female.

Education. Education was assessed and analyzed as a categorical variable defined as 1 = some grade school, 2 = junior high/8th grade, $3=$ some high school, $4=G E D, 5=$ graduated high school, $6=1-2$ years college, no degree, $7=3+$ years college, no degree, $8=2$-year college degree, $9=4$-year college degree, $10=$ some graduate school, $11=$ master's degree, and $12=$ doctoral degree.

Total household income. Household income was a continuous variable with a range of $\$ 0$ to $\$ 300,000$ per year.

Environmental. Environmenal antecedents included measures of social support and predictability. Social support included measures of partner, family, and friend support (Walen \& Lachman, 2000). Each was assessed by four questions: (a) How much does your spouse [family] [friend] really care about you?" (b) "How much does he or she [they] understand the way you feel about things?" (c) "How much can you rely on him or her [them] for help if you have a serious problem?" and (d) "How much can you open up to him or her [them] if you need to talk about your worries?" Response choices ranged from $1=$ a lot to $4=$ not at all. Each was recoded from the original so higher scores reflected higher perceived support. A mean score for each domain of support was calculated for those participants who answered at least one of the questions from each domain. A collective mean of the three domain scores served as an overall measure of social support. Cronbach's alpha was .54 for Study 1 and .61 for Study 2 .

A one-item measure was used to assess respondent's reporting of the predictability of their future. The item read, "I am good at predicting what is going to happen to me." Responses, reverse scored from their original, ranged from $1=$ not at all, $2=$ a little, $3=$ some, and $4=a$ lot .

Personality. Personality was assessed via the self-descriptive attributes from the MIDI, Questionnaire I (see Lachman \& Weaver, 1998). The Big Five personality constructs (McCrae \& Costa, 1985) Agreeableness, Conscientiousness, Extraversion, Neuroticism, and Openness to Experience were examined. Participants were asked to indicate how well each dimension described them on a scale ranging from $1=a$ lot to $4=$ not at all. There were 25 items in total. Responses were reverse coded when necessary so that the higher the scores the more closely that dimension described them. Alphas were as follows: Agreeableness (helpful, warm, caring, softhearted, sympathetic) $=.80$; Conscientiousness (organized, responsible, hardworking, careless) $=.58$; Extraversion (outgoing, friendly, lively, talkative, active) $=.78 ;$ Neuroticism (moody, worrying, nervous, calm) $=$ .74; Openness (creative, imaginative, intelligent, adventurous, curious, broadminded, sophisticated) $=.78$.

Stress in this study was operationalized as the number of stressful events from two sources, others and self. Others' stressful events were assessed by responses to 30 items regarding participants' spouse or partner, parents, and their own children. Respondents indicated whether the person (spouse, parent, or child) had experienced any of the target "problems" within the past 12 months. Examples included chronic health problems, alcohol or substance abuse problems, legal problems, and difficulty finding or keeping a job. Responses were recoded so that $1=y e s$ and $0=$ no; a higher score indicated more stressful events. Each source received a summed score, and then a mean of the three (spouse or partner, parents, and 


\begin{tabular}{|c|c|c|c|c|c|c|c|c|c|c|}
\hline 7 & 8 & 9 & 10 & 11 & 12 & 13 & 14 & 15 & 16 & 17 \\
\hline $.07 * * *$ & $.04 *$ & -.02 & $-.16^{* * *}$ & -.08 & -.03 & & & $-.07 * * *$ & $-.10 * * *$ & $.15^{* * *}$ \\
\hline $.27^{* * *}$ & $.10^{* * *}$ & $.07 * * *$ & $.13^{* * *}$ & $-.08 * * *$ & $.10^{* * *}$ & & & $-.15 * * *$ & $-.11^{* * *}$ & -.03 \\
\hline$-.10^{* * *}$ & $.10^{* * *}$ & -.03 & $-.09 * * *$ & $.22 * * *$ & $-.03^{*}$ & & & $.29 * * *$ & $.20^{* * *}$ & $.08 * * *$ \\
\hline$-.10 * * *$ & $.12 * * *$ & .01 & $-.06^{* * *}$ & $.08^{* * *}$ & $-.02 * *$ & & & $.20 * * *$ & $.17 * * *$ & $.17 * * *$ \\
\hline $.27 * * *$ & $.22 * * *$ & $.32 * * *$ & $-.20 * * *$ & $.19 * * *$ & $-.21 * * *$ & & & $.19 * * *$ & $.35^{* * *}$ & $.44 * * *$ \\
\hline $10^{* * * *}$ & $.14 * * *$ & $20 * * *$ & $-.08 * * *$ & $32 * * *$ & -.01 & & & $.17 * * *$ & $.17 * * *$ & $.10 * * *$ \\
\hline - & $.31 * * *$ & $.54 * * *$ & $-.04 *$ & $.35 * * *$ & .00 & & & .01 & $.12 * * *$ & $.18 * * *$ \\
\hline $.32 * * *$ & - & $.27 * * *$ & $-.19 * * *$ & $.26 * * *$ & $-.10 * * *$ & & & $.26 * * *$ & $.33 * * *$ & $.29 * * *$ \\
\hline $.47^{* * * *}$ & $.24 * * *$ & - & $-.15 * * *$ & $.53 * * *$ & $-.11 * * *$ & & & $.14 * * *$ & $.30^{* * *}$ & $.28 * * *$ \\
\hline-.08 & $-.29 * * *$ & -.08 & - & $-.14 * * *$ & $.29 * * *$ & & & $-.10 * * *$ & $-.26 * * *$ & $-.35 * * *$ \\
\hline $.30 * * *$ & $.26 * * *$ & $.47 * * *$ & $-.15^{* *}$ & - & $-.03 *$ & & & $.26 * * *$ & $.32 * * *$ & $.16 * * *$ \\
\hline-.04 & $-.14 *$ & -.05 & $.20^{* *}$ & .04 & - & & & $-.26 * * *$ & $-34 * * *$ & \\
\hline$-.14 *$ & $-.15^{*}$ & .05 & -.06 & .09 & .03 & - & & & & \\
\hline-.08 & .01 & .04 & $-.16 * *$ & $.15^{* * *}$ & $-.09^{* *}$ & $.51 * * *$ & - & & & \\
\hline .05 & $.24 * * *$ & $.13 *$ & $-.19 * *$ & $.31 * * *$ & $-.19 * * *$ & $.15 * *$ & $.24^{* * *}$ & - & $.43 * * *$ & $.20 * *$ \\
\hline .11 & $.31 * * *$ & $30 * * *$ & $-.42 * * *$ & $.34 * * *$ & $-.23 * * *$ & .10 & $.22 * * *$ & $.47 * * *$ & - & $.44 * * *$ \\
\hline $.13^{*}$ & $.27 * * *$ & $.28^{* * * *}$ & $-.39 * * *$ & $.15^{* * *}$ & $-.33 * * *$ & .03 & $.12^{*}$ & $.29^{* *}$ & $.46^{* * * *}$ & - \\
\hline
\end{tabular}

children), based on the number of categories applicable, was computed. Scores had a possible range of $0-30$.

Similarly, stressful events for self were assessed from work and finances, partner, and health domains. Five items were used to assess stressful events from work/finances. Participants were asked if they had experienced any of the following five events during the past 12 months ( $1=$ yes and $0=$ no): (a) temporarily laid off, (b) serious ongoing problem getting along with someone at work, (c) other serious ongoing stress at work, (d) serious difficulty paying monthly bills, and (e) poor chance of keeping present job. Possible range of scores was $0-5$. Stressful health events were measured with a 29 -item health symptom checklist. Participants were asked to report whether they had experienced any health disorders (e.g., asthma, cancer, heart attack, diabetes) during the past 12 months $(1=$ yes and $0=n o)$. Possible range of scores was $0-29$. Partner stress was assessed via a four-item Likert scale measure. Responses were recoded so that $1=$ never, $2=$ rarely, $3=$ sometimes, and $4=$ ofien. Items asked participants, (a) "How often does your spouse or partner make too many demands on you?" (b) "How' often does he or she criticize you?" (c) "How often does he or she let you down when you are counting on him or her?" and (d) "How often does he or she get on your nerves?" A mean of the four items was computed as a measure of stress from partner. These three self-stress domains (work/finances, health, partner) were summed to produce a total stressful events for self score. Scores of stressful events for self had a possible range of $4-38$. Both stressful events scores (from others and for self) were standardized to $z$ scores, and a mean value was computed for an overall measure of stressful events such that the higher the score the more stressful events experienced. Scores ranged from -1.86 to 6.60 for Study $I$ and -1.38 to 3.28 for Study 2. Cronbach's alpha for Study I was .77 and .66 for Study 2.

Cognitive. Measures of working memory span and problem solving/ reasoning were examined as cognitive correlates of planning. These measures were available for 288 participants from Study 2. Participants with missing values $(n=12)$ were assigned the mean for their age group (young, middle, or old) to ensure consistent sample size across analyses. Measures of working memory span included the Wechsler Adult Intelligence Scale-Revised (WAIS-R) Forward and Backward Digit Span (Wechsler, 1981) and a counting backward task. In the WAIS-R Forward Digit Span each string of numbers was read, one digit per second, by the interviewer, and the participants attempted to repeat the string in forward order. Each participant had two trials (with different digit strings). If the string was repeated correctly on the first trial, a string one digit greater in length was given. Assessments progressed until the participant produced two incorrect strings of the same length. The respondent's score was the highest level at which at least one string was repeated correctly. Scores ranged from 0 to 7 . The WAIS-R Backward Digit Span and scoring proceeded in much the same manner as described above except that the participant was instructed to repeat the string in backward order from which it was presented. In the counting backward task, participants counted backward by $7 \mathrm{~s}$ starting at 478 . Each participant was given $1 \mathrm{~min}$ to give as many correct responses as possible. Scores were calculated as the number of correct responses. The standardized mean ( $z$ score) of the three measures was calculated and used as a single measure of working memory (L. S. Miller \& Lachman, 2000). Higher scores represented better working memory span. Scores ranged from -3.05 to 2.24 . Cronbach's alpha was .67 .

The Raven's (Raven, Court, \& Raven, 1994) Advanced Progressive Matrices (APM) and the Schaie-Thurstone Letter Series Test (Schaie, 1985) were used as measures of problem solving/reasoning. In the Raven's APM, when presented with an abstract figure or group of figures, from which one area was missing, participants were required to determine which single piece, from eight options presented, completed the given pattern correctly. Three practice items were presented, followed by 18 (evennumbered) test items. Participants had $20 \mathrm{~min}$ to complete the task. Scores represented the number correct out of 18. Items not attempted or completed before time was up were counted as incorrect. The Letter Series Test required participants to complete a series of given letters with the letter (from among five choices) that comes next in the string. After five practice problems (for which they were given the correct answers) they were given $6 \mathrm{~min}$ to complete as many items as possible out of 30 . Scores represented the number of correct responses. The standardized ( $z$ score) mean of the two scores (APM and Letter Series) was used as an indicator of problem solving/reasoning (Miller \& Lachman, 2000). Scores ranged from -2.03 to 2.42 . Cronbach's alpha was .76 .

Future planning. For this study, future planning was defined as a self-reported, future-oriented planning style of life management. A fiveitem, continuous planning scale was developed. The five items, taken from 
the MIDI mailed questionnaire, consisted of the following: (a) "I like to make plans for the future." (b) "I find it helpful to set goals for the near future." (c) "I live one day at a time." (d) "I have too many things to think about today to think about tomorrow." (e) "I believe there is no sense planning too far ahead because so many things can change." These items were based on a 4-point Likert scale format: $1=a$ lot, $2=$ some, $3=a$ little, and $4=$ not at all. Participants were asked to indicate how much each item described them. Items 1 and 2 were reverse coded $(4=a$ lot and $1=$ not at all) so higher scores reflected increased future-oriented planning. Scores ranged from 1.20 to 4.00 for Study 1 and 2.40 to 3.20 for Study 2 . Cronbach's alpha was assessed at .63 for Study 1 and .67 for Study 2 .

Perceived control. Perceived control was measured by averaging two control subscales (personal mastery and perceived constraints) consisting of 12 items (see Lachman \& Weaver, 1998; Pearlin \& Schooler, 1978). Each of the items was assessed on a 7-point scale. Personal mastery items included: "I can do just about anything I set my mind to," and "What happens to me in the future mostly depends on me." Perceived constraint items included: "There is little I can do to change the important things in my life," and "What happens to me is often beyond my control" (see Lachman \& Weaver, 1998, for a full description of the measure). Items on the personal mastery scale were reverse coded such that $7=$ strongly agree to 1 = strongly disagree. This was done to create internally consistent scales and to create a unidimentional scale in which the higher the obtained score, the more perceived control. Because there was a significant correlation between the two subscales for both studies $(r=-.40$ for Study 1 and $r=-.47$ for Study 2 ) and no differential predictions were made regarding the predictive ability of personal mastery and perceived constraints, perceived control was assessed as a unidimensional construct by averaging the scores of the two dimensions (personal mastery and perceived constraints). Scores had a possible range of 1.0-7.0. Alpha coefficients were assessed at .85 for Studies 1 and 2.

Life satisfaction. To assess life satisfaction a four-item scale was constructed. Assessing life overall, work, health, and family (the mean of ratings for relationship with spouse/partner and relationship with children), each question asked: "On a scale of 0 to 10 where 0 means the worst and 10 means the best how would you rate your ficients were .67 for Study 1 and .69 for Study 2 .
Results

\section{Descriptive Statistics}

Means, standard deviations, and correlations for the demographic variables, predictor variables, and outcome variables for both studies are presented in Table 1. They suggest that the two samples were very similar across a majority of the measures. Participants in Study 2 were slightly older, had slightly more years of education, and reported a higher total household income. A clear majority of the predictor variables and the demographic variables were significantly correlated with planning, perceived control, and life satisfaction.

\section{Predicting Planning}

We used multiple regression analysis to examine the relationships between the predictor variables and future planning. Demographics were entered first so their effects could be controlled as other antecedent variables were entered. The environmental and personality/motivational variables were entered as a second step. Finally, the cognitive variables were entered last, as they were only available for Study 2 and we wanted to replicate, as well as extend, results when comparing the two samples. As hypothesized, there were variations in planning by demographic indicators-Study 1: $F(4,2949)=87.61, p<.001, R^{2}=.11$; Study $2: F(2$, $299)=18.72, p<.001, R^{2}=.21$-and environmental and personality indicators-Study $1: F(11,2949)=72.61, p<.001$, $R^{2}=.21$; Study $2: F(11,299)=11.30, p<.01, R^{2}=.32$. Although cognitive factors were added to the model they were not significantly related to future-oriented planning. Results for both studies are presented in Table 2.

Demographics. Gender, education, and income were found to be predictive of future-oriented planning styles for both studies. In both studies, men were more future oriented in their strategies than

Table 2

Summary of Regression Analysis Predicting Planning in Studies $1(N=2,950)$ and $2(N=300)$

\begin{tabular}{|c|c|c|c|c|c|c|c|c|}
\hline \multirow[b]{2}{*}{ Predictor variable } & \multicolumn{4}{|c|}{ Study 1} & \multicolumn{4}{|c|}{ Study 2} \\
\hline & $B$ & $S E B$ & $\beta$ & Total $R^{2}$ & $B$ & $S E B$ & $\beta$ & Total $R^{2}$ \\
\hline \multicolumn{9}{|l|}{ Step 1} \\
\hline Age & -.02 & .00 & $-.06^{* * *}$ & $.11^{* * *}$ & -.001 & .00 & -.02 & $.21 * * *$ \\
\hline Gender & -.11 & .02 & $-.10^{* * *}$ & & -.20 & .07 & $-.16 * *$ & \\
\hline Education & .04 & .00 & $.17 * * *$ & & .06 & .01 & $.24 * * *$ & \\
\hline Income & .00 & .00 & $.07 * * *$ & & .00 & .00 & $.15^{* *}$ & \\
\hline \multicolumn{9}{|l|}{ Step 2} \\
\hline Support & .20 & .02 & $.10^{* * *}$ & $.21^{* * *}$ & .12 & .06 & $.11^{* *}$ & $.32 * *$ \\
\hline Predictability & -.12 & .01 & $.05 * * *$ & & .10 & .04 & $.14^{*}$ & \\
\hline Agreeableness & .02 & .03 & $-.08 * * *$ & & -.01 & .07 & -.01 & \\
\hline Conscientiousness & -.17 & .02 & $.18^{* * *}$ & & .16 & .08 & $.11^{*}$ & \\
\hline Extraversion & .05 & .02 & .01 & & -.01 & .07 & -.01 & \\
\hline Neuroticism & .30 & .02 & $-.10 * * *$ & & -.04 & .05 & -.04 & \\
\hline Openness & .15 & .02 & $.14 * * *$ & & .18 & .08 & $.14^{*}$ & \\
\hline Stressful events & .00 & .01 & -.01 & & -.02 & .02 & -.05 & \\
\hline \multicolumn{9}{|l|}{ Step $3^{\mathrm{a}}$} \\
\hline Memory & & & & & -.03 & .05 & -.04 & .32 \\
\hline Reasoning & & & & & .05 & .05 & .07 & \\
\hline
\end{tabular}

${ }^{a}$ For Study 2 only.

$* p<.05 . \quad * * p<.01 . * * * p<.001$. 
Table 3

Summary of Regression Analysis Predicting Perceived Control in Studies $1(N=2,971)$ and 2 $(N=300)$

\begin{tabular}{|c|c|c|c|c|c|c|c|c|}
\hline \multirow[b]{2}{*}{ Predictor variable } & \multicolumn{4}{|c|}{ Study 1} & \multicolumn{4}{|c|}{ Study 2} \\
\hline & $B$ & $S E B$ & $\beta$ & Total $R^{2}$ & $B$ & $S E B$ & $\beta$ & Total $R^{2}$ \\
\hline \multicolumn{9}{|l|}{ Step 1} \\
\hline Age & -.006 & .00 & $-.08 * * *$ & $.06 * * *$ & -.007 & .004 & -.10 & $.07 * * *$ \\
\hline Gender & -.17 & .04 & $-.08 * * *$ & & -.14 & .11 & -.07 & \\
\hline Education & .06 & .01 & $.14 * * *$ & & .07 & .02 & $.18^{* *}$ & \\
\hline Income & .00 & .00 & $.11^{* * *}$ & & .00 & .00 & .09 & \\
\hline \multicolumn{9}{|l|}{ Step 2} \\
\hline Agreeableness & -.08 & .04 & -.04 & $.33 * * *$ & -.12 & .10 & -.07 & $.34 * * *$ \\
\hline Conscientiousness & .45 & .04 & $.20 * * *$ & & .34 & .12 & $.16 * *$ & \\
\hline Extraversion & .30 & .04 & $.16 * * *$ & & .39 & .11 & $.21 * * *$ & \\
\hline Neuroticism & -.52 & .03 & $-.33 * * *$ & & -.52 & .08 & $-.35 * * *$ & \\
\hline Openness & .23 & .04 & $.12 * * *$ & & .24 & .11 & $.13 *$ & \\
\hline \multicolumn{9}{|l|}{ Step 3} \\
\hline Planning & .45 & .03 & $.25^{* * *}$ & $.38 * * *$ & .47 & .08 & $.31 * * *$ & $.40^{* * *}$ \\
\hline
\end{tabular}

women, and participants with both higher education and income were more future oriented. Age was a significant predictor in Study 1; older adults were less likely to engage in future-oriented planning.

Environmental precursors. Social support and predictive ability were significantly related to planning style in both studies. These results suggest that the greater one's perception of social support, measured here as support from family, friends, and spouse/partner, the more likely they were to report more futureoriented planning. Ability to predict what will happen was also significantly related to planning. The greater the reported predictability, the more future oriented their planning style.

Personality precursors. Personality and motivation antecedents were also significant predictors. In Study 1, Neuroticism and Agreeableness were both negatively related to future-oriented planning, whereas Conscientiousness and Openness to Experience were positively related. Extraversion and stressful events were not significantly predictive. In Study 2, only Conscientiousness and Openness were predictive of planning style.

Cognitive precursors. Cognitive measures of both working memory span and reasoning were assessed for Study 2. Both had no significant predictive ability as evidenced by a nonsignificant $F$ change in the regression model. We examined both cognitive components separately (working memory and reasoning) and as a single composite score, which also did not change the outcome. We estimated a model without education and found a marginally significant ( $p=.07$; change in beta from .07 to .12) effect of the APM and Letter Series composite for planning.

\section{Planning, Perceived Control, and Life Satisfaction}

To address the question of planning's influence on perceived control and life satisfaction and to examine the mediational effects (Baron \& Kenny, 1986) of control for planning, we first assessed the relationship between future planning and perceived control and then the association of planning and life satisfaction. Centered versions of the age and planning variables were computed and used in the model to minimize multicollinearity with the Age $\times$ Planning interaction term.

Planning and perceived control. To assess the nature of the relationship between future-oriented planning and perceived control and to test the hypothesis that future-oriented planning would have a positive impact on perceived control, we used multiple regression analysis (see Table 3 ). To test the effect of planning on perceived control, demographic and personality variables were entered first to control for their influences. Results for both studies indicated that when controlling for demographic and personality variables, future planning was significantly and positively related to perceived control-Study 1: $F(10,2970)=180.65, p<.001$, $R^{2}=.38$; Study 2: $F(10,299)=19.61, p<.001, R^{2}=.40{ }^{1}$

Men reported greater perceived control than did women in Study 1 but not in Study 2. Younger participants reported a greater sense of perceived control than did older participants, although this was only statistically significant in Study 1. In both studies higher education was related to greater perceived control, and in Study 1 higher income was also predictive of perceived control. All of the Big Five personality variables were predictive of perceived control for Study 1 and Study 2 with the exception of Agreeableness.

Planning and life satisfaction. Regression analysis for planning and life satisfaction tested the hypothesis that participants who reported more future-oriented planning would also report greater life satisfaction. We also included an Age $\times$ Planning interaction term to examine how the relationship of planning and life satisfaction might vary by age.

To examine the effects of planning on life satisfaction, the demographic and personality variables were entered first, on

\footnotetext{
${ }^{1}$ Because of the significant correlation between planning and predictability, we conducted supplementary regression analyses, substituting predictability for planning when predicting perceived control. Predictability was a significant predictor of perceived control for Study $1(p=.05)$ but not for Study 2, suggesting that planning was more consistently related to control than predictability.
} 
Steps 1 and 2 , respectively. Age and income were positively predictive of life satisfaction in both samples. Results for Study 1 showed Agreeableness, Conscientiousness, and Extraversion to be positively related to life satisfaction, whereas Neuroticism and Openness were negatively related. For Study 2 only Neuroticism was negatively related. On Step 3 the planning and interaction terms were entered. The hypothesis that future planning would predict life satisfaction was supported for both studies - Study 1: $F(11,2971)=85.06, p<.001$; Study $2: F(11,300)=8.97, p<$ .01 (see Table 4). Additionally, results revealed a significant Age $\times$ Planning interaction (see Figure 1) for Study 1 . The figure shows that although planning was associated with higher life satisfaction for all age groups, the effects were greatest for the oldest group.

\section{The Mediation of Planning Effects by Control Beliefs}

To further investigate the relationship of future-oriented planning, perceived control, and life satisfaction, we tested a mediational model. Our model examined the mediational effect of control on planning when predicting life satisfaction. We used the Baron and Kenny (1986) four-step mediational method and present our final models for Study 1 and Study 2 in Table 4. In Steps 1 and 2 , demographic and personality variables were predictive of life satisfaction as mentioned above. Step 3, in the final model, shows that the centered planning and Planning $\times$ Age interaction variables were no longer significant predictors of life satisfaction after perceived control was entered on Step 4. The degree of mediation was assessed by using a version of a test originally proposed by Sobel (1982) and modified by Baron and Kenny (see D. T. Gilbert, Fiske, \& Lindzey, 1998). For both Study 1 and Study 2 results indicated a significant reduction of the effect of planning on life satisfaction. Planning was no longer a significant predictor of life satisfaction when perceived control was entered as a predictor variable, suggesting full mediation-Study 1: $z=11.68, p<.001$; Study $2: z=4.48, p<.001$. In Study 1 beta coefficients for the planning and interaction terms were reduced from .08 and .04 to .00 and .02 , respectively. For Study 2 the change was from .18 and -.04 to .05 and -.05 , respectively.

\section{Discussion}

This study had two goals: first, to examine antecedents of self-reported planning styles, and second, to explore the relationship between planning, perceived control, and life satisfaction. Consistent with the model of planning presented by S. L. Friedman and Scholnick (1997), environmental, and personality factors were demonstrated to be predictive of planning. The cognitive measures examined in Study 2 were not related to future planning as postulated. Perhaps most important, results indicated that future planning was related to life satisfaction and that the nature of this relationship varied by age. Those who were more future oriented had greater life satisfaction, and in Study 1 this relationship was more pronounced for older adults as evidenced by a significant Age $\times$ Planning interaction. These results were further bolstered by the finding that control beliefs mediated the effects of planning and the Planning $\times$ Age interaction, suggesting that planning for the future facilitates a sense of perceived control for all age groups, which enhances life satisfaction. In the few cases in which the relationships of specific variables (i.e., Agreeableness, Conscientiousness, Extraversion, and Openness) to life satisfaction were not statistically significant in Study 2, the direction of the patterns was the same as in Study 1. Although sample size for Study 2 was smaller, power analysis suggested an adequate sample size to

Table 4

Summary of Regression Analysis for the Mediational Effects of Control for Planning When Predicting Life Satisfaction in Studies $I(N=2,971)$ and $2(N=300)$

\begin{tabular}{|c|c|c|c|c|c|c|c|c|}
\hline \multirow[b]{2}{*}{ Predictor variable } & \multicolumn{4}{|c|}{ Study 1} & \multicolumn{4}{|c|}{ Study 2} \\
\hline & $B$ & $S E B$ & $\beta$ & Total $R^{2}$ & $B$ & $S E B$ & $\beta$ & Total $R^{2}$ \\
\hline \multicolumn{9}{|l|}{ Step 1} \\
\hline Ảge & .01 & .00 & $.14^{* * *}$ & $.05 * * *$ & .01 & .00 & $.14^{* *}$ & $.06 * *$ \\
\hline Gender & .04 & .04 & .01 & & .15 & .14 & .06 & \\
\hline Education & -.01 & .00 & -.02 & & -.05 & .03 & -.10 & \\
\hline Income & .00 & .00 & $.11 * * *$ & & .00 & .00 & $.13^{*}$ & \\
\hline \multicolumn{9}{|l|}{ Step 2} \\
\hline Agreeableness & .19 & .05 & $.07 * *$ & $.22 * * *$ & .00 & .15 & .00 & $.23 * * *$ \\
\hline Conscientiousness & .27 & .05 & $.09 * * *$ & & .16 & .17 & .06 & \\
\hline Extraversion & .32 & .05 & $.14 * * *$ & & .29 & .16 & .11 & \\
\hline Neuroticism & -.33 & .04 & $-.17 * * *$ & & -.41 & .12 & $-.19 * *$ & \\
\hline Openness & -.23 & .05 & $-.09 * *$ & & -.26 & .16 & -.10 & \\
\hline \multicolumn{9}{|l|}{ Step 3} \\
\hline Planning & .00 & .04 & .00 & .22 & .13 & .17 & .05 & .23 \\
\hline Planning $\times$ Age & .00 & .00 & .02 & & -.00 & .00 & -.05 & \\
\hline \multicolumn{9}{|l|}{ Step 4} \\
\hline Control & .52 & .03 & $.32 * * *$ & $.29 * * *$ & .74 & .11 & $.41 * * *$ & $.31 * * *$ \\
\hline
\end{tabular}

Note. Coefficients are from the final four-step model. Before the addition of control on Step 4 , the planning term significantly predicted life satisfaction for both studies (Study $1: B=.18, \beta=.08^{* * *}, R^{2}=.24^{* * *}$; Study 2: $B=.40, \beta=.18^{* *}, R^{2}=.25^{* *}$ ) and the Planning $\times$ Age interaction term significantly predicted life satisfaction in Study $1(B=.01, \beta=.04 *)$. The interaction term was not significant for Study 2.

${ }^{*} p<.05 . \quad{ }^{* *} p<.01 . \quad{ }^{* * *} p<.001$. 


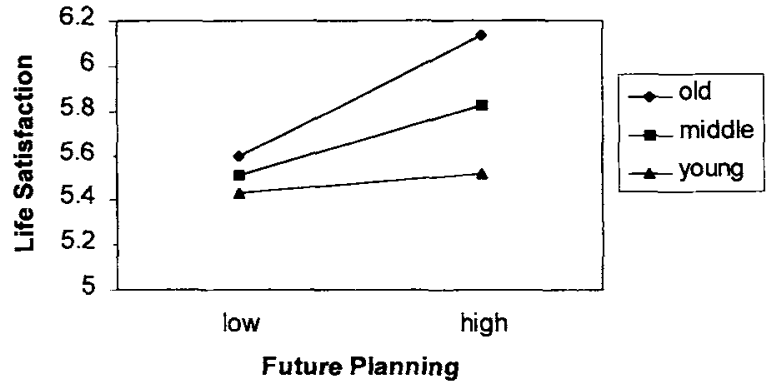

Figure 1. Interaction of age and planning in predicting adjusted means for life satisfaction from Study $1(N=2,971)$.

detect significant differences with small effect sizes $(.20$; see Cohen \& Cohen, 1983). Power ranged from .82 to .99 across different effects.

\section{Predicting Planning}

As a first goal, this study examined antecedent demographic, social/environmental, personality/motivational, and cognitive variables in relation to future-oriented life-planning styles. An examination of demographic indices revealed that sex, education, and income were all positively predictive of planning for both studies. Men reported more future-oriented planning than did women. This study, however, did not control for the influence of gender/family roles and their influence of future planning. The traditional male familial role of family provider (L. A. Gilbert, 1985) may influence men to take a more long-term, generalized planning approach, whereas women, in the role of wife, mother, or both, may be too busy with day-to-day logistics of raising a family, requiring women to take on more immediate tasks, supporting findings by Burack and Lachman (1996), who reported women to be more short-term, or "list making," planners than are men. Future research controlling for men's and women's gender/family roles (Bouffard et al., 1996; Mintz \& Mahalik, 1996) and examining differences between women working outside the home to those working exclusively within the home as full-time homemakers (Boswell, 1981; Weitz, 1977) may shed some light on this interesting finding. Consistent with previous research, this study also found a positive relationship between education and income and the futurity of planning. Nurmi (1992) has demonstrated that more highly educated people expect that negative (e.g., poor health) issues concerning them will be realized later in life, therefore influencing them to adopt a more optimistic attitude regarding the future. This more optimistic attitude is likely to be reflected in increased future-oriented planning.

Age differences in the futurity of planning were found for Study 1 . The significant negative relationship suggests that as age increased, self-reports of future-oriented planning decreased. These findings were not significant for Study 2; however, the directionality of the regression coefficient was consistent with those of Study 1 . These findings were also consistent with previous cross-sectional research suggesting that as age increases, people's temporal extension decreases (e.g., Cameron et al., 1977-1978; Fingerman \& Perlmutter, 1995; Rakowski, 1979).

The environmental predictors, social support and predictability, were also positively associated with future planning. According to
Hudson et al. (1997), an essential component of children's planning is "external support" (p. 79). These results suggest that social support may be important for adults as well. Predictability was also significantly related to future-oriented planning. Uncertainty of future events may lead to decreased planning or a lack of effective planning strategies (M. I. Friedman \& Lackey, 1991).

The hypothesis that personality precursors would significantly predict future planning was supported in both studies. Agreeableness and Neuroticism were negatively related to future planning in Study 1, suggesting that individuals who are more neurotic and agreeable may be less motivated to think about the future. One might speculate that someone who is very agreeable (i.e., warm and caring) may be more compliant and influenced by others in order to avoid competitiveness and maintain social harmony (Graziano, Hair, \& Finch, 1997). Their goals may be more influenced by what others want, thereby reducing the need for making future plans. Similarly, individuals who are more neurotic may be more likely to be consumed with problems and worries in the present and may not feel the desire or ability to think too far ahead. Conscientiousness and Openness were both positively associated with future-oriented planning. Conscientious people may feel a desire to plan for the future so that they will be ready for whatever may come their way, whereas Openness to Experience may motivate people to be ready for the future. Extraversion was unrelated to planning in both studies.

Stressful events were assessed as a motivational component influencing future-oriented planning. Previous findings showing a negative impact of stress on decision making (Locke et al., 1997) and planful behavior in children (Kopp, 1997) suggest that if individuals were experiencing what they perceived to be a high degree of stress they would be less likely to plan for the future. For both studies the experience of stressful events was unrelated to planning. These results suggest that the experience of stressful events does not necessarily equate to perceived stress or that stress may play a less significant role in planning of more long-term life goals than in more problem-focused planning (Locke et al., 1997) or in children's planning strategies (Kopp, 1997).

Previous research with children (Haith, 1997) suggests that working memory is a necessary precursor of planning. Although for Study 2 working memory span was demonstrated to be significantly, positively correlated with planning $(r=.15, p<.01)$, it was not predictive of planning in the final regression model. Working memory may be more important for short-term, immediate problem-solving planning (Haith, 1997) and not as important for the more temporally extended life management planning styles assessed here. Further study should be undertaken to either replicate these findings or to focus on the issue of general planning styles versus the temporal nature of planning styles as they are related to working memory in adulthood.

Using the APM and Letter Series Test as measures of problem solving/reasoning yielded no significant relationship with planning style. Again, although reasoning skills were positively correlated with future planning ( $r=.24, p<.001)$ they failed to produce significant results in the final regression model after controlling for other variables, including education. These correlational findings, although consistent with previous research that investigated simultaneous and successive processing and general planning strategies (Das et al., 1996; S. L. Friedman \& Scholnick, 1997), suggest that these cognitive processes may not be directly related to or predic- 
tive of the temporal nature of life planning. Additional research into cognitive influences on life planning is suggested. Specific attention should be paid to the differentiation of problem-solving planning and daily-life planning.

\section{Planning, Perceived Control, and Life Satisfaction}

A second goal of this study was to investigate the relationship between planning style, perceived control, and life satisfaction. Results supported both previous research and our hypotheses that futureoriented planning would predict perceived control (Kirschenbaum et al., 1981) and life satisfaction (Mahon, Yarcheski, \& Yarcheski, 1997; Spence, 1968)

To further assess the relationship between age, planning, and life satisfaction, we used an interaction in the regression analysis. Although older adults reported less future planning overall compared with younger age groups, the effects of planning on life satisfaction were most pronounced for older adults. This finding may have significant implications with respect to interventions designed to enhance outcomes for older adults. It has been suggested (Carstensen, Isaacowitz, \& Charles, 1999) that age-related patterns of future-time perspective can be altered. Encouraging older adults to continue to plan for the future, even in the face of its diminished temporality, may lead to greater life satisfaction. Qualitative support for this interpretation is apparent from answers to one of the open-ended questions included in Study 2: "What do you do to manage your daily life?" A 64-year-old respondent with high life satisfaction and future planning indicated, "I get up every day, plan a $9-5$ schedule Monday through Friday. ... The rest is planning five months ahead." In contrast, a 73-year-old participant who scored below the median on life satisfaction and future planning responded to the same question by saying, "I just get up and stumble through it."

The hypothesized mediational relationship between planning style, control, and life satisfaction was supported, suggesting that planning may have its effect on life satisfaction because it imparts a greater sense of perceived control over one's life. These results not only lend further support for the idea that a greater sense of control is positively related to well-being (e.g., Bond \& Feather, 1988; Brandtstädter \& Baltes-Gotz, 1990; Burack \& Lachman, 1995; Eronen et al., 1997; Lachman \& Burack, 1993; Macan et al., 1990; Skinner, 1997) but also begin to address the process involved in planning and life management. Future research into this question should consider a more broad-based and differentiated measure of planning and a more multidimensional assessment of life satisfaction than the four-item measure used here. The use of a multiitem, multidomain measure may facilitate a more in-depth understanding of what constitutes life satisfaction in relation to planning.

Limitations of this study include the cross-sectional nature of the data. S. L. Friedman and Scholnick (1997) presented their model of planning as a process of development, so that longitudinal data would be valuable. Their antecedent variables were based on research in developmental psychology. We cannot say here that environmental or personality aspects of our participants' lives caused them to become more future oriented in their planning styles. We can only apply their model to our cross-sectional data and suggest that these variables were significantly related to participants' reporting of future-oriented planning styles. Similarly, we can only suggest that these results present information on the relationship between individuals' reports of their planning orientation and their concurrent reporting of perceived control and life satisfaction. Additionally, the precise nature of the relationship between planning, control, and life satisfaction needs to be more thoroughly specified. It is possible that people of any age who are more satisfied with their current life situation or who have a greater sense of control may be more inclined to plan. Because of the cross-sectional nature of the data, however, we could not test these possibilities.

Other limitations of this study include the reliability and validity of the measures used. Although alphas were generally at or above accepted levels, some were marginal (.58 for Conscientiousness and .54 and .61 for social support) and need to be taken into consideration when interpreting and generalizing results. The use of an existing data set limited the availability of alternative items with which to construct scales.

The two-study format of this research enabled a replication of our findings by using two probability samples, one large sample from the United States and one smaller, local sample from the Greater Boston area. The findings are a useful beginning to address the process whereby planning affects life satisfaction through the influence of perceived control. The significant Age $\times$ Planning interaction in Study 1 is especially noteworthy as it provides additional insight into the previously accepted notion that as people age they decrease the futurity of their planning. Although future-oriented planning may diminish on average, it is still a valuable life management strategy in later life.

\section{References}

Aspinwell, L. G. (1997). Planning and perceived control. In S. L. Friedman \& E. K. Scholnick (Eds.), The developmental psychology of planning: Why, how, and when do we plan? (pp. 285-320). Mahwah, NJ: Erlbaum. Bandura, A. (1997). Self-efficacy: The exercise of control. New York: Freeman.

Baron, R. M., \& Kenny, D. A. (1986). The moderator-mediator variable distinction in social psychological research: Conceptual, strategic, and statistical considerations. Journal of Personality and Social Psychology, 5I, 1173-1182.

Bond, M. J., \& Feather, N. T. (1988). Some correlates of structure and purpose in the use of time. Journal of Personality and Social Psychology, 55, 321-329.

Boswell, J. (1981). The dual-career family: A model for egalitarian family politics. Elementary School Guidance and Counseling, 15(3), 262-268.

Bouffard, L., Bastin, E., \& Lapierre, S. (1996). Future time perspective according to women's age and social role during adulthood. Sex Roles, 34, 253-285.

Brandtstädter, J., \& Baltes-Gotz, B. (1990). Personal control over development and quality of life perspectives in adulthood. In P. Baltes \& M. Baltes (Eds.), Successful aging (pp. 197-221). Melboume, Australia: Press Syndicate of the University of Cambridge.

Bronfenbrenner, U. (1979). The ecology of human development. Cambridge, MA: Harvard University Press.

Burack, O. R., \& Lachman, M. E. (1995, August). The use and benefits of time management strategies in adulthood. Poster presented at the 103rd Annual Convention of the American Psychological Association, New York.

Burack, O. R., \& Lachman, M. E. (1996). The effects of list-making on recall in young and elderly adults. Journal of Gerontology, 51, 226-233. Cameron, P., Desai, K. G., Bahador, D., \& Dremel, G. (1977-1978). 
Temporality across the life-span. International Journal of Aging and Human Development, 8, 229-259.

Cantor, N. (1990). From thought to behavior: "Having" and "doing" in the study of personality and cognition. American Psychologist, 45, 735-750.

Carstensen, L. L., Isaacowitz, D. M., \& Charles, S. T. (1999). Taking time seriously: A theory of socioemotional selectivity. American Psychologist, 54, 165-181.

Cohen, J., \& Cohen, P. (1983). Applied multiple regression/correlation analysis for the behavioral sciences. Hillsdale, NJ: Erlbaum.

Das, J. P., Kar, B. C., \& Parrilla, R. K. (1996). Cognitive planning: The psychological basis of intelligent behavior. New Deli, India: Sage.

Eronen, S., Nurmi, J., \& Salmela-Aro, K. (1997). Planning-oriented, avoidant, and impulsive social reaction styles: A person-oriented approach. Journal of Research in Personality, 31, 34-57.

Fingerman, K., \& Perlmutter, M. (1995). Future time perspective and life events across adulthood. Journal of General Psychology, 122, 95-111.

Friedman, M. 1., \& Lackey, G. H. (1991). The psychology of human control: A general theory of purposeful behavior. New York: Praeger.

Friedman, S. L., \& Scholnick, E. K. (1997). The developmental psychology of planning: Why, how, and when do we plan? Mahwah, NJ: Erlbaum.

Gilbert, D. T., Fiske, S. T., \& Lindzey, G. (1998). The handbook of social psychology (4th ed.). New York: Oxford University Press.

Gilbert, L. A. (1985). Men in dual-career families: Current realities and future prospects. Hillsdale, NJ: Erlbaum.

Gollwitzer, P. M. (1996). The volitional benefits of planning. In P. Gollwitzer \& J. A. Bargh (Eds.), The psychology of action (pp. 287-312), New York: Guilford Press.

Goodnow, J. J. (1997). The interpersonal and social aspects of planning. In S. L. Friedman \& E. K. Scholnick (Eds.), The developmental psychology of planning: Why, how, and when do we plan? (pp. 339-357). Mahwah, NJ: Erlbaum.

Graziano, W. G., Hair, E. C., \& Finch, J. F. (1997). Competitiveness mediates the link between personality and group performance. Journal of Personality and Social Psychology, 73, 1394-1408.

Haith, M. M. (1997). The development of future thinking as essential for the emergence of skill in planning. In S. L. Friedman \& E. K. Scholnick (Eds.), The developmental psychology of planning: Why, how, and when do we plan? (pp. 25-42). Mahwah, NJ: Erlbaum.

Haith, M. M., Benson, J. B., Roberts, R. J., \& Pennington, B. F. (1996). Introduction. In M. M. Haith, J. B. Benson, R. J. Roberts, \& B. F. Pennington (Eds.), The development of future-oriented processes (pp. 1-7). Chicago, IL: University of Chicago Press.

Hudson, J. A., Sosa, B. B., \& Shapiro, L. R. (1997). Scripts and plans: The development of preschool children's event knowledge and event planning. In S. L. Friedman \& E. K. Scholnick (Eds.), The developmental psychology of planning: Why, how, and when do we plan? (pp. 77-102). Mahwah, NJ: Erlbaum.

Kastenbaum, R. (1963). Cognitive and personal futurity in later life. Journal of Individual Psychology, 19, 216-222.

Kirschenbaum, D. S., Humphrey, L. L., \& Malett, S. D. (1981). Specificity of planning in adult self-control: An applied investigation. Journal of Personality and Social Psychology, 40, 941-950.

Kopp, C. B. (1997). Young children: Emotion management, instrumental control, and plans. In S. L. Friedman \& E. K. Scholnick (Eds.), The developmental psychology of planning: Why, how, and when do we plan? (pp. 103-124). Mahwah, NJ: Erlbaum.

Kuhl, J. (1984). Volitional aspects of achievement motivation in learned helplessness: Toward a comprehensive theory of action control. In B. A. Maber (Ed.), Progress in experimental personality research (pp. 99171). New York: Academic Press.

Kunde, D. (1998, December 28). Trying to get a grip on time in a warp-speed world: Day planners help produce order out of chaos at work. The Dallas Morning News, p. C-4.

Lachman, M. E., \& Burack, O. R. (1993). Planning and control processes across the life span: An overview. In M. E. Lachman (Ed.), Planning and control processes across the life span (pp. 131-143). East Sussex, England: Erlbaum.

Lachman, M. E., \& Weaver, S. L. (1998). The sense of control as a moderator of social class differences in health and well being. Journal of Personality and Social Psychology, 74, 763-773.

Lens, W., \& Gailly, A. (1980). Extension of future time perspective in motivational goals of different age groups. International Journal of Behavioral Development, 3, 1-17.

Lessing, E. E. (1968). Demographic, developmental, and personality correlates of length of future time perspective (FTP). Journal of Personality, 36, 183-201.

Little, B. R. (1983). Personal projects: A rationale and method for investigation. Environment and Behavior, 15, 273-309.

Locke, E. A., Durham, C. C., Poon, J. M. L., \& Weldon, E. (1997). Goal setting, planning, and performance on work tasks for individuals and groups. In S. L. Friedman \& E. K. Scholnick (Eds.), The developmental psychology of planning: Why, how, and when do we plan? (pp. 239262). Mahwah, NJ: Erlbaum.

Lowenthal, M. F., Thurnher, M., \& Chiriboga, D. (1975). Four stages of life: A comparative study of men and women facing transitions. San Francisco: Jossey-Bass.

Luria, A. (1966). Higher cortical functions in man. New York: Basic Books.

Macan, T. H. (1994). Time management: Test of a process model. Journal of Applied Psychology, 79, 381-391.

Macan, T. H., Shahani, C., Dipboye, R. L., \& Phillips, A. P. (1990). College students' time management: Correlations with academic performance and stress. Journal of Educational Psychology, 82, 760-768.

Mahon, N. E., Yarcheski, T. J., \& Yarcheski, A. (1997). Future time perspective and positive health practices in young adults: An extension. Perceptual and Motor Skills, 84, 1299-1304.

McCrae, R. R., \& Costa, P. T. (1985). Comparison of EPI and psychoticism scales with measures of the five-factor model of personality. Personality and Individual Differences, 6, 587-597.

Miller, G. A., Galanter, E., \& Pribram, K. H. (1960). Plans and the structure of behavior. Holt, Rinehart, and Winston.

Miller, L. S., \& Lachman, M. E. (2000). Cognitive performance and the role of control beliefs in midlife. Aging Neuropsychology and Cognition, 7, 69-85.

Mintz, R. D., \& Mahalik, J. R. (1996). Gender role orientation and conflict as predictors of family roles for men. Sex Roles, 34, 805-821.

Nurmi, J. E. (1989). Development of orientation to the future during early adolescence: A four-year longitudinal study and two cross-sectional comparisons. Intemational Journal of Psychology, 24, 195-214.

Nurmi, J. E. (1992). Age differences in adult life goals, concerns, and their temporal extension: A life course approach to future-oriented motivation. International Journal of Behavioral Development, 15, 487-508.

Nuttin, J. R., \& Lens, W. (1985). Future time perspective and motivation: Theory and research method. Hillsdale, NJ: Erlbaum.

Pearlin, L., \& Schooler, C. (1978). The structure of coping. Journal of Health and Social Behavior, 19, 2-21.

Rakowski, W. (1979). Future time perspective in later adulthood: Review and research directions. Experimental Aging Research, 5, 43-88.

Raven, J. C., Court, J. H., \& Raven, J. (1994). Raven manual: Section 4. Advanced progressive matrices (4th ed.). Oxford, England: Oxford Psychologist Press.

Robertson, S. A. (1978). Some personality correlates of time competence, temporal extension, and temporal evaluation. Perceptual and Motor Skills, 46, 743-750.

Rogoff, B. (1990). Apprenticeship in thinking. New York: Oxford University Press.

Schaie, K. W. (1985). Manual for the Schaie-Thurstone Adult Mental 
Abilities Test (STAMAT). Palo Alto, CA: Consulting Psychologists Press.

Schneiderman, L. (1964). Value orientation preferences of chronic relief recipients. Journal of Social Work, 9, 13-19.

Scholnick, E. K., \& Friedman, S. L. (1993). Planning in context: Developmental and situational considerations. In M. E. Lachman (Ed.), Planning and control processes across the life span (pp. 145-167). East Sussex, England: Erlbaum.

Skinner, E. A. (1997). Planning and perceived control. In S. L. Friedman \& E. K. Scholnick (Eds.), The developmental psychology of planning: Why, how, and when do we plan? (pp. 263-284). Mahwah, NJ: Erlbaum. Smith, J. (1996). Planning about life: Toward a social-interactive perspective. In P. Baltes \& U. Staudinger (Eds.), Interactive minds (pp. 242275). Cambridge, England: Cambridge University Press.

Sobel, M. E. (1982). Asymptotic confidence intervals for indirect effects in structural models. In S. Leinhardt (Ed.), Sociological methodology 1982 (pp. 290-312). San Francisco: Jossey-Bass.

Spence, D. L. (1968). The role of futurity in aging adaptation. Gerontologist, 8, 180-183.

Teahan, J. E. (1958). Future time perspective, optimism, and academic achievement. Journal of Abnormal and Social Psychology, 57, 379-380.

Thompson, S. C., Cheek, P. R., \& Graham, M. A. (1988). The other side of perceived control: Disadvantages and negative effects. In S. Spacapan \& S. Oskamp (Eds.), The social psychology of health (pp. 69-93). Newbury Park, CA: Sage

Trommsdorff, G. (1994). Future time perspective and control orientation: Social conditions and consequences. In Z. Zaleski (Ed.), Psychology of future orientation (pp. 39-62). Lublin, Poland: Towarzystwo Naukowe KUL.

Trommsdorff, G., Lamm, H., \& Schmidt, R. (1978). A longitudinal study of adolescents' future orientation (time perspective). Journal of Youth and Adolescence, 8, 131-147.

Walen, H. E., \& Lachman, M. E. (2000). Social support and strain from partner, family and friends: Costs and benefits for men and women in adulthood. Journal of Social and Personal Relationships, 17(1), 5-30.

Wechsler, D. (1981). Wechsler Adult Intelligence Scale-Revised. New York: Psychological Corporation.

Weitz, S. (1977). Sex roles: Biological, psychological, and social foundations. New York: Oxford University Press.

Received September 28, 1999

Revision received April 2, 2000

Accepted June 20, 2000

\section{Low Publication Prices for APA Members and Affiliates}

Keeping you up-to-date. All APA Fellows, Members, Associates, and Student Affiliates receive-as part of their annual dues-subscriptions to the American Psychologist and APA Monitor. High School Teacher and International Affiliates receive subscriptions to the APA Monitor, and they may subscribe to the American Psychologist at a significantly reduced rate. In addition, all Members and Student Affiliates are eligible for savings of up to $60 \%$ (plus a journal credit) on all other APA journals, as well as significant discounts on subscriptions from cooperating societies and publishers (e.g., the American Association for Counseling and Development, Academic Press, and Human Sciences Press).

Essential resources. APA members and affiliates receive special rates for purchases of APA books, including the Publication Manual of the American Psychological Association, and on dozens of new topical books each year.

Other benefits of membership. Membership in APA also provides eligibility for competitive insurance plans, continuing education programs, reduced APA convention fees, and specialty divisions.

More information. Write to American Psychological Association, Membership Services, 750 First Street, NE, Washington, DC 20002-4242. 